\title{
Value Domain
}

National Cancer Institute

\section{Source}

National Cancer Institute. Value Domain. NCI Thesaurus. Code C42748.

Specified by a description or specification, such as a rule, a procedure, a range (i.e. interval), or by a set of permissible values. 